\title{
JORNALISMO DIGITAL: Pesquisa multifacetada no desenvolvimento de didáticas e processos de produção
}

DIGITAL JOURNALISM: Multifacetered research in the development of didactics and production processes

PERIODISMO DIGITAL: Investigación polifacética en el desarrollo de didácticas y procesos productivos

\section{Zanei Ramos Barcellos}

Doutor em Gestão Urbana, mestre em Administração, bacharel em Comunicação Social - Jornalismo. Professor adjunto de Jornalismo Digital e pesquisador no Departamento de Jornalismo da Faculdade de Comunicação da Universidade de Brasília (FAC/UnB). E-mail: zaneibarcellos@unb.br;

0000-0001-8619-6056

Correspondência: Universidade Federal do Tocantins, Reitoria, DIRETORIA DE COMUNICAÇÃO. Quadra 109 Norte Avenida NS 15, Plano Diretor Norte, 77001090 Palmas, TO - Brasil.

Recebido em: 16.02.2021.

Aceito em: 16.04.2021.

Publicado em: 01.07.2021.

RESUMO:

A internet é a principal fonte de notícias dos brasileiros, o smartphone o aparelho preferido de acesso a elas e as redes sociais superaram a televisão como meio

\begin{abstract}
jornalístico hegemônico. $\mathrm{O}$ jornalismo fragmentado no ciberespaço demanda novas narrativas, formatos de veículos, processos de produção e distribuição. Os algoritmos e sistemas da inteligência artificial (IA) já desempenham muitas tarefas, a profissão se reconfigura e o ensino do jornalismo digital precisa acompanhar as transformações. Este artigo propõe a pesquisa aplicada multifacetada como forma de desenvolver narrativas, aparatos, sistemas de gerenciamento de produção e didáticas capazes acompanhar as evoluções tecnológicas e formar jornalistas aptos à pesquisa e ao trabalho em ambientes mutantes.
\end{abstract}

PALAVRAS-CHAVES: Jornalismo digital; pesquisa aplicada; multiplataforma; inteligência artificial.

\section{Introdução}

O Digital News Report 2020 (REUTERS INSTITUTE FOR THE STUDY OF JOURNALISM, 2020) revelou que $87 \%$ dos brasileiros têm a internet como principal fonte de notícias e que as redes sociais (67\%) ultrapassaram a televisão (66\%) como meio preferido de acesso às notícias.

O mesmo levantamento mostrou o smartphone estável (76\%) como aparelho predileto de acesso às notícias digitalizadas, enquanto o notebook (43\%) continuou em queda e o tablet (10\%) estável. Estes dados significativos para o jornalismo tornam-se ainda mais relevantes quando considera-se a circulação de 234 milhões de chips de celulares no país em julho de 2020, conforme a $31^{\text {a }}$ Pesquisa Anual do Uso de TI nas Empresas (FGV-EAESP, 2020).

No mesmo empenho de relacionar o consumo de jornalismo às tecnologias comunicacionais, a pesquisa TIC Domicílios 2019 (CETIC.BR, 2020), mostrou a preferência de $98 \%$ dos brasileiros conectados pelo smartphone para o acesso à 
internet e que entre as principais motivações estão usar as redes sociais (65\%) e buscar informações (68\%), atividades que podem incluir o consumo de notícias.

A mesma pesquisa Cetic revelou ainda que $56 \%$ dos entrevistados leem jornais e revistas online, enquanto o Digital 2020 April Global Statshotl (WE ARE SOCIAL, 2020) levantou que $76 \%$ dos usuários de internet nos 17 países pesquisados, Brasil incluso, passaram a usar mais seus smartphones para acessar a rede devido à pandemia.

Enquanto isso, o uso de aplicativos por mobiles cresceu exponencialmente nos últimos anos. O Global Benchmarks Report (ADJUST GLOBAL APP TRENDS, 2019) colocou o Brasil como o segundo país onde a utilização de aplicativos mais aumentou (9,39\%) em 2018, ano em que o uso de apps de notícias e de redes sociais no planeta cresceu respectivamente 2,11 e 2,29\%.

Este ambiente organizacional leva os veículos jornalísticos e conglomerados comunicacionais a desenvolvem seus próprios softwares aplicativos empresariais para mobiles (apps) destinados principalmente a facilitar o acesso às notícias, disparar avisos, reforçar marcas e fidelizar leitores. A adaptação dos apps de notícias às necessidades do receptor diferencia as empresas comunicacionais entre si e pode levar à preferência por uma ou outra em mercado de intensa concorrência.

A inserção das tecnologias emergentes nos diversos processos do fazer e da difusão jornalísticos é ininterrupta e intrínseca à atividade. Um dos aspectos tecnológicos mais relevantes para o jornalismo na atualidade é a busca pelo domínio e aplicação dos algoritmos e inteligência artificial (IA) nas suas atividades. Mesmo os veículos sem grandes somas para desenvolver ou comprar sistemas da IA e algoritmos podem valer-se dos fluxos comunicacionais gerados pelos algoritmos e sistemas de IA inerentes à web para autonomamente encaminhar ao receptor a notícia por ele esperada, no horário ideal e no formato adequado ao aparelho disponível, processo denominado Jornalismo das Coisas por Barcellos et al (2017). Esse processo pode extrapolar o mero aproveitamento dos fluxos comunicacionais quando otimizado por algoritmos desenvolvidos pelos veículos jornalísticos em harmonia com as suas próprias estratégias organizacionais.

Porém, o uso dos fluxos gerados pelos algoritmos e IA de outrem e mesmo a performance dos sistemas desenvolvidos pelos próprios veículos jornalísticos na rede estão sujeitos a restrições e conflitos no ciberespaço. Quando qualquer sistema informacional entra na web, pode harmonizar-se com alguns aspectos dos algoritmos e sistemas de IA dominantes, mas também conflitar-se com eles, com os interesses e objetivos de quem os produziu. Os algoritmos dominantes são hegemonicamente produzidos pelas grandes corporações digitais, como Google, Apple, Facebook e 
Amazon, que estrategicamente não revelam completamente o seu funcionamento nem intenções (PARISER, 2012; GALLOWAY, 2017). Algumas destas grandes corporações restringem os fluxos de certas informações na rede, apropriam-se de conteúdos jornalísticos com produção bancada pelos veículos e até faturam com publicidade cobrada sobre acessos às notícias.

Isto faz com que a relação entre os veículos de comunicação e os grandes da internet seja mundialmente tensa e motivo de confrontos regionalizados. Em vários países e blocos econômicos estes conflitos de interesses geraram normas e legislações específicas para preservar a cidadania e a livre-concorrência. Este cenário de conflito no ciberespaço foi antevisto por Gibson (1984) até certo ponto na sua obra ficcional Neromancer.

Assim, a universidade precisa formar pesquisadores e jornalistas aptos ao trabalho em ambiente incerto e volátil devido às velozes evoluções das tecnologias comunicacionais. Diante disso, este artigo objetiva descrever uma pesquisa aplicada multifacetada em realização que visa desenvolver didáticas, narrativas, processos de produção e sistemas informatizados para o jornalismo digital.

A artigo começa com o entrelaçamento de algumas referências teóricas com aspectos da prática do jornalismo digital. A descrição das atividades do jornal conectada ao referencial teórico vem na sequência, ao mesmo tempo em que se apresenta o jornal digital Campus Multiplataforma, a configuração das suas plataformas e processos de produção. O jornal em questão é o objeto e o destino das pesquisas em foco. Na sequência estão listadas pesquisas correlatas à principal encerradas e em desenvolvimento, seguidas de algumas ponderações sobre seus resultados e direcionamentos futuros. O artigo termina com considerações sobre pesquisa aplicada voltada à produção e ao ensino do jornalismo digital.

\section{Referencial teórico-prático}

A ação dos veículos jornalísticos, dos jornalistas e dos atores comuns na internet pode potencializar ou minimizar o alcance da notícia conforme as programações dos algoritmos e alcance dos sistemas de inteligência artificial (IA) que permeiam a web de forma geral e especificamente nas redes sociotécnicas. Quanto mais desvendarem sobre o funcionamento dos algoritmos, mais os jornalistas podem programar publicações em determinados horários e locais do ciberespaço, e usar outras técnicas de search engine optimization (SEO) para potencializar a visibilidade das notícias e segmentar públicos. Os algoritmos e os sistemas de IA inerentes à rede, portanto, assumem funções de gatekeepers e segmentadores de públicos ao 
determinarem a quem e quais notícias a eles chegam, e também os meios, formatos e os momentos de entrega. Os atores comuns, por sua vez, ao comentarem e compartilharem as notícias também exercem papel de gatekeepers, ou gatewatchers, como tipifica Bruns (2009). Quando agem desta forma, os atores comuns transmidiatizam a notícia na posição de prosumers (TOFFER, 1980), até conferindo-lhes novos sentidos (BARCELLOS ET AL, 2017; BRUNS, 2009; CASTELLS, 1999; DIAKOUPOULUS, 2019a; DIAKOUPOULUS, 2019b; HANSEN ET AL, 2017; JENKINS, GREEN, FORD, 2014; JENKINS, 2008).

O descongelamento da recepção pressupõe complexificação na produção de notícias. As antigas salas de redação físicas centralizadoras do processamento das notícias rumam à virtualização do trabalho espraiado no ciberespaço. Nesta realidade, o jornalista perde algumas funções para a automação e ganha novas relacionadas à programação e às tecnologias. Outras profissões entram nas redações e ganham estatus de jornalistas.

As notícias agora são processadas diferentemente em cada conglomerado comunicacional. A necessidade de produção multimídia concomitante destinada a várias plataformas demanda processos de produção e distribuição céleres e complexos, porém flexíveis e impermanentes. Esses processos ocorrem mais eficientemente em redações convergentes (JENKINS, 2008), automatizadas e virtualizadas. Barcellos, Gonzatto e Bozza (2014) concebem redação virtual como:

Local do ciberespaço onde os jornalistas trabalham de forma suficiente e sinérgica sem necessitar de espaço físico compartilhado. Assim, paradoxalmente, pode-se dizer que a produção jornalística se dá de forma dispersa, sem reunir os profissionais no mesmo espaço físico, mas centralizada e/ou coordenada, no mais das vezes concomitante, em um "lugar" do ciberespaço que se torna também ambiente de destino da produção, onde é processada e de onde é distribuída para o consumo. (BARCELLOS, GONZATTO, BOZZA, 2014, P. 85)

A difusão do smartphone e a cultura da mobilidade também implicaram em novos modelos de negócios para o jornalismo. O celular inteligente passou a instrumentalizalizar várias facetas do jornalismo convergente e multiplataforma (WESTLUND, 2013) até conquistar o protagonismo na distribuição de notícias. O smartphone como principal forma de acesso à notícia significa também novas formas de interação entre o receptor e a informação. A rolagem de tela e o clique do computador foram substituídos pelo touch screem e a notícia tornou-se ubíqua. 
Atravessamos uma barreira psicológica... No desktop e no tablet, pode-se ficar em uma zona de conforto do fac-símile onde a experiência fundamental é surpreendentemente semelhante à de ler um jornal. Mas a área de trabalho está caindo como uma pedra. Agora é a vez dos smartphones. Tudo deve funcionar no smartphone. ${ }^{1}$ (KUENG, 2017, p. 27 - Em tradução livre do autor)

Em consequência, as pesquisas sobre os efeitos das mídias sociais, do smatphone e da IA na prática do jornalismo difundiram-se rapidamente nos últimos anos e constataram, entre outras coisas, mais interação entre os jornalistas e os públicos (HOLTON, LEWIS e CODDINGTON, 2016); a desritualização do consumo e a fragmentação das notícias (LIVINGSTON, 2004); a associação entre as plataformas tradicionais com as digitais, o surgimento de veículos nato-digitais (BIVENS, 2008); o uso de algoritmos e inteligência artificial na produção e distribuição de notícias (BUCHER, 2012; LATZER, 2016; DIAKOPOULOS, 2019a; DIAKOPOULOS, 2019b); o surgimento de novas rotinas de produção e configurações das redações (ROBINSON, 2011); os valores emergentes para a seleção das notícias e as reflexões éticas sobre a profissão (DEUZE e WITSCHGE, 2018; DEUZE e YESHUA, 2001; MICROSOFT, 2018).

\section{O macro objeto e a organicidade da pesquisa}

O macro objeto da pesquisa em apresentação é o jornal laboratório Campus Multiplataforma. Também é nele que os resultados são primeiramente aplicados. $O$ Campus Multiplataforma foi criado em março de 2017 na disciplina Campus Multimídia, curricular obrigatória no curso de Jornalismo da Faculdade de Comunicação da Universidade de Brasília (FAC/UnB). A média de alunos matriculados semestralmente é 25 e a carga horária soma 12 horas semanais. A pesquisa aplicada macro em apresentação começou junto com o jornal e prossegue indefinidamente.

O jornal inclui sete plataformas: um web aplicativo de desenvolvimento próprio, o AppCampus; um site, também de desenvolvimento próprio; um grupo de distribuição de notícias no WhatsApp, uma página no Facebook, um perfil no Instagram, um perfil no Twitter e um canal no YouTube. Todas as plataformas do Campus narram fatos para a comunidade da UnB, instituição pública de ensino superior fundada em 1962, com quatro campi no Distrito Federal e cerca de 57 mil estudantes, professores e funcionários - uma das maiores do Brasil.

\footnotetext{
${ }^{1}$ We've been through a psychological barrier. On desktop and on tablet you can stay in a facsimile comfort zone where the fundamental experience is surprisingly like reading the paper. But desktop is falling like a stone. It's smartphones. Everything must work on the smartphone.
} 
As pesquisas relacionadas ao Campus perpassam a disciplina e se cruzam com outras de professores e alunos (trabalhos de conclusão de cursos, iniciação científica e grupos de pesquisa) da Faculdade de Comunicação e de outras unidades da UnB.

A linha editorial do Campus Multiplataforma é fundamentada no jornalismo cívico de Traquina (2003, 2005) e nos preceitos de Castells (2012). Assim, o jornal posiciona-se ao lado do cidadão em pretende ser ambiente virtual de deliberação democrática. A gestão também é participativa como forma de inclusão, de minimizar as possibilidades de erros individuais, de fomentar a criatividade, de proporcionar processos sinérgicos de inteligência coletiva e de estabelecer discussões internas permanentes para fomentar o aprendizado (BARBOSA, MOURA, 2013; FREIRE, 1974, 1985, 1993; LEVY, 1999). A atuação dos alunos como pesquisadores e criadores segue a metodologia Pesquisa Criação, que não separa o pesquisador do objeto e valoriza a experimentação de novos elementos, entre os quais as narrativas midiáticas (CHAPMAN e SAWCHUK, 2012).

O Campus desenvolveu uma estrutura organizacional na qual foram definidas as funções de todos os seus integrantes (Figura 1). O organograma varia conforme a definição de cada grupo. Procurou-se um formato organizacional horizontal, com poucos degraus hierárquicos e sem chefias isoladas. Um Conselho Editorial assume semestralmente o comando colegiado da produção em vez de atribuí-lo a um único diretor ou secretário de redação. O mediador do projeto (e professor) se incluiu no Conselho Editorial em nível hierárquico igual aos demais, com a menor interferência possível no processo, mas à disposição dos alunos para estimular discussões sobre ética ou abordagem editorial. A estrutura com repórteres não atrelados a nenhuma editoria favorece a cobertura da mesma notícia simultaneamente para várias plataformas e nas mídias apropriadas.

Da mesma forma, a estrutura facilita a formatação das notícias em diferentes narrativas multimídias, convergência midiática e a transmidiatização da notícia. No Campus, as narrativas puras que caracterizavam as mídias tradicionais se hibridizam e são publicadas em diferentes formatos e suportes digitais, de onde podem linkar-se entre si. Formam assim uma teia narrativa permissiva às interferências dos prosumers, receptores agora com o dom da transmidiação e que interferem ativamente na produção e na difusão das notícias (CASTELLS, 1999; JERKINS, 2008; JERKINS, GREEN e FORD, 2014; SCOLARI, 2011; TOFFLER,1980).

Outro aspecto da convergência presente no Campus é a produção de notícias para recepção preferencial pelo smartphone. Esta decisão editorial assumiu o mobile como aparelho convergente. No smartphone o AppCampus agrega todas as notícias e 
funciona como ambiente de entrada às sete plataformas, acessíveis com apenas um toque.

Figura 1 Estrutura Organizacional do Campus Multiplataforma.

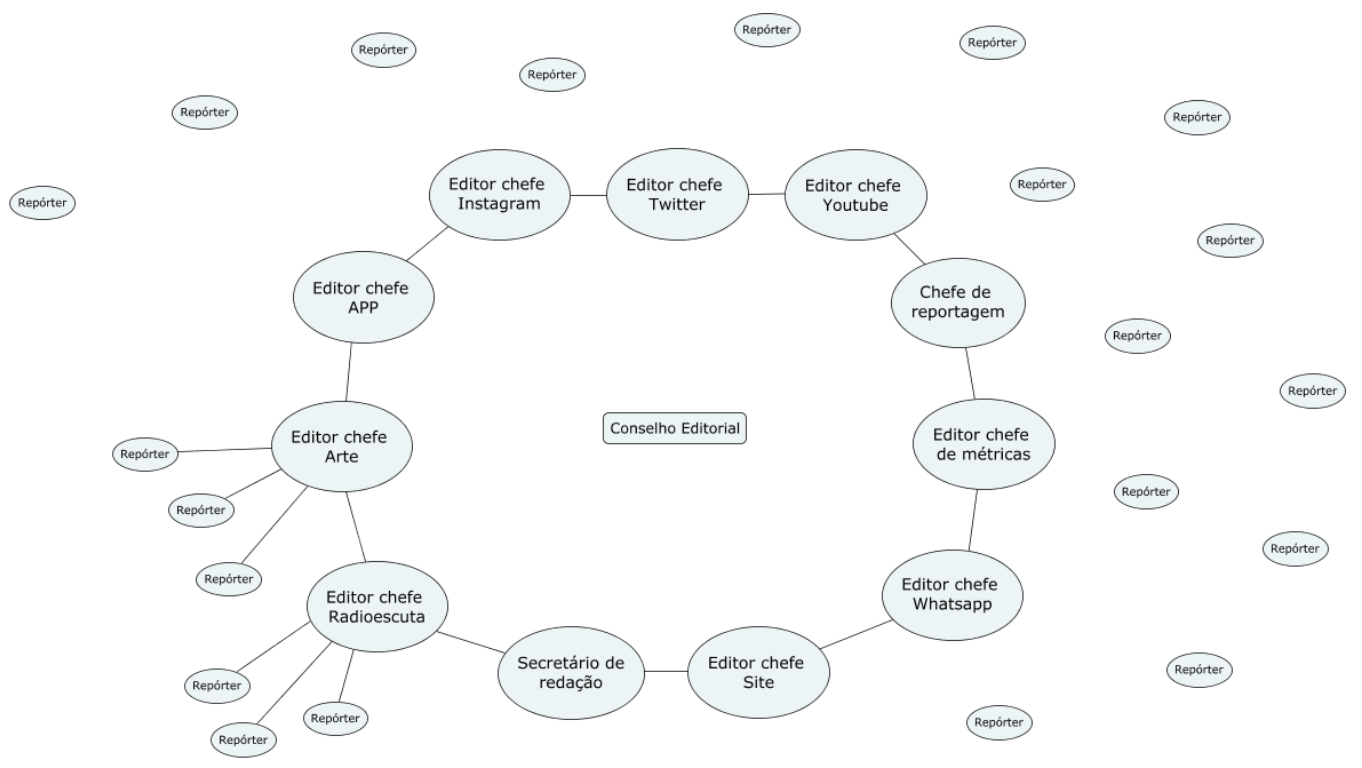

Fonte: Cópia de Barcellos e Silva (2020, p. 8)

A didática adotada incentiva que todas as atividades inerentes à produção e distribuição das notícias do Campus sejam realizadas com o smartphone. Realização de entrevistas; produção e edição de vídeos, fotos, áudios e textos; comunicação interna e externa; envio e recebimento de arquivos; postagens e interatividade. Como esses processos se dão em regime de redação virtual, o smartphone assume também nela o protagonismo.

A redação virtual adotada pelo Campus Multiplataforma se caracteriza como convergente porque neste ambiente se produzem notícias para diferentes plataformas. O Campus, por sua vez, se caracteriza como multiplataforma porque, de acordo com Salaverría (2005), o jornalismo multiplataforma estrategicamente envolve a atuação de vários meios de comunicação articuladamente para a realização de coberturas jornalísticas.

A opção pela produção e difusão do noticário pelo smartphone foi tomada pelo grupo fundador do Campus Multiplataforma durante a realização de dinâmicas freirianas e metodologias ativas (FREIRE, 1974, 1985, 1993; BARBOSA e MOURA, 2013). A decisão coincidiu com a adoção do bordão "smartphone first" pelo The New York Times, que marcou a prioridade do jornal pelo mobile como plataforma de distribuição de notícias. 
A breve reflexão sobre as posturas didáticas, de produção e distribuição adotadas em relação à prática do jornal Campus Multiplataforma traduz um pouco o processo orgânico permanente da pesquisa aplicada macro, seus fundamentos teóricos, aspectos práticos, aplicação dos resultados, formulação de didática, retroalimentação de pesquisas e cruzamentos. A reflexão apresentada está ampliada a seguir com a descrição de dinâmicas e resultados de sub-pesquisas.

\section{Pesquisas agregadas}

As várias pesquisas aplicadas agregadas à principal são bem delineadas e independentes, com metodologias e cronogramas próprios, porém se cruzam, se interpenetram, se complementam, se retroalimentam. São testadas na prática e aplicadas nas atividades didáticas e laboratoriais da disciplina Campus Multimídia. Os resultados são periodicamente apresentados e publicados em eventos, bancas, livros e revistas.

Os procedimentos em descrição seguem os preceitos de Trujillo Ferrari (1982), para quem a pesquisa científica aplicada extrapola sua finalidade prática e "pode contribuir teoricamente com novos fatos para o planejamento de novas pesquisas ou mesmo para a compreensão teórica de certos setores do conhecimento" (p. 171). O uso de diferentes metodologias harmoniza-se com o pensamento de outros pesquisadores que concordam entre si que a pesquisa aplicada pode valer-se de diferentes procedimentos metodológicos e atender simultaneamente a múltiplos grupos de interesse (FLEURY e WERLANG, 2017).

O Quadro 1 resume algumas as pesquisas agregadas em desenvolvimento, em implantação ou já encerradas com resultados em aplicação. Estão comentadas no capítulo apenas as pesquisas em andamento e em implantação, uma vez que as demais já foram divulgadas em outras publicações.

Quadro 1 Pesquisas aplicadas vinculadas à macro pesquisa Campus Multiplataforma.

\begin{tabular}{|c|c|c|}
\hline $\begin{array}{c}\text { Discriminação da } \\
\text { pesquisa e estágio de } \\
\text { desenvolvimento }\end{array}$ & $\begin{array}{c}\text { Descrição resumida } \\
\text { e suporte teórico }\end{array}$ & $\begin{array}{c}\text { Principais procedimentos } \\
\text { metodológicos }\end{array}$ \\
\hline $\begin{array}{c}\text { Desenvolvimento de } \\
\text { didática para o ensino } \\
\text { e prática do } \\
\text { jornalismo Digital } \\
\text { - Desenvolvida. } \\
\begin{array}{c}\text { Resultados em } \\
\text { aplicação }\end{array}\end{array}$ & $\begin{array}{c}\text { Didática freiriana e baseada em } \\
\text { metodologias ativas, aberta e flexível } \\
\text { capaz de assimilar rapidamente } \\
\text { evoluções tecnológicas e vislumbrar } \\
\text { suas aplicações ao jornalismo. } \\
\text { (FREIRE, 1974, 1985, 1993; BARBOSA } \\
\text { e MOURA, 2013) }\end{array}$ & $\begin{array}{c}\text { Pesquisa criação - } \\
\text { Modalidade que não separa } \\
\text { pesquisador do objeto, } \\
\text { valoriza a experimentação de } \\
\text { novos elementos, incluindo } \\
\text { narrativas midiáticas. } \\
\text { (CHAPMAN e SAWCHUK, } \\
\text { 2012) }\end{array}$ \\
\hline
\end{tabular}




\begin{tabular}{|c|c|c|}
\hline $\begin{array}{l}\text { Criação de veículo } \\
\text { jornalístico } \\
\text { multiplataforma } \\
\text { • Desenvolvida. } \\
\text { Resultados em } \\
\text { aplicação }\end{array}$ & $\begin{array}{l}\text { Veículo jornalístico distribuído em } \\
\text { várias plataformas digitais para } \\
\text { publicação de notícias diferenciadas e } \\
\text { adequadas às características de cada } \\
\text { uma delas (redes sociotécnicas, apps } \\
\text { de mensagens e jornalísticos e sites) } \\
\text { (SALAVERRÍA, 2005) }\end{array}$ & $\begin{array}{c}\text { Pesquisa criação } \\
\text { (CHAPMAN e SAWCHUK, } \\
\text { 2012) }\end{array}$ \\
\hline $\begin{array}{l}\text { Desenvolvimento de } \\
\text { narrativas jornalísticas } \\
\text { - Desenvolvida. } \\
\text { Resultados em } \\
\text { aplicação em } \\
\text { constante atualização }\end{array}$ & $\begin{array}{c}\text { Criação de narrativas próprias para } \\
\text { diferentes redes sociotécnicas, sites, } \\
\text { apps de mensagens e jornalísticos } \\
\text { considerando as características de } \\
\text { cada um e seus espaços diferenciados } \\
\text { de publicação }\end{array}$ & $\begin{array}{c}\text { Pesquisa criação } \\
\text { (CHAPMAN e SAWCHUK, } \\
\text { 2012) }\end{array}$ \\
\hline $\begin{array}{l}\text { Produção de } \\
\text { jornalismo } \\
\text { preferencial para e } \\
\text { por smartphone } \\
\text { - Desenvolvida. } \\
\text { Resultados em } \\
\text { aplicação }\end{array}$ & $\begin{array}{l}\text { Uso do smartphone como plataforma } \\
\text { jornalística e formatação de notícias } \\
\text { apropriadas à recepção por mobile. } \\
\text { Trabalho de produção jornalística e } \\
\text { distribuição de notícias via } \\
\text { smartphone }\end{array}$ & $\begin{array}{c}\text { Pesquisa criação } \\
\text { (CHAPMAN e SAWCHUK, } \\
\text { 2012) }\end{array}$ \\
\hline $\begin{array}{l}\text { Implantação de } \\
\text { Redação Virtual } \\
\text { • Desenvolvida. } \\
\text { Resultados em } \\
\text { aplicação }\end{array}$ & $\begin{array}{l}\text { Realização de todas as tarefas } \\
\text { jornalísticas remotamente } \\
\text { (planejamento, levantamento de } \\
\text { dados e entrevistas, comunicação } \\
\text { interna, tráfego interno de conteúdos, } \\
\text { publicação e interação com } \\
\text { receptores) (BARCELLOS, GONZATTO } \\
\text { e BOZZA, 2014) }\end{array}$ & $\begin{array}{c}\text { Pesquisa criação } \\
\text { (CHAPMAN e SAWCHUK, } \\
\text { 2012) }\end{array}$ \\
\hline $\begin{array}{l}\text { Desenvolvimento de } \\
\text { processo de produção } \\
\text { em rede (workflow) } \\
\text { • Desenvolvida. } \\
\text { Resultados em } \\
\text { aplicação }\end{array}$ & $\begin{array}{l}\text { Mapeamento e desenho do } \\
\text { fluxograma de todo o processo de } \\
\text { tomada de decisões, de produção de } \\
\text { conteúdos e de distribuição de } \\
\text { notícias do Campus Multiplataforma. } \\
\text { (AALST e HEE, 2000). }\end{array}$ & $\begin{array}{c}\text { Estudo de caso (GEORGE e } \\
\text { BENNETT, 2005; STAKE, } \\
\text { 2005), observação } \\
\text { participante } \\
\text { (MALINOWSKI,1978), } \\
\text { entrevistas semiestruturadas } \\
\text { e pesquisa bibliográfica } \\
\text { (MARCONI e LAKATOS,1996), }\end{array}$ \\
\hline $\begin{array}{l}\text { Aproveitamento dos } \\
\text { fluxos } \\
\text { comunicacionais dos } \\
\text { algoritmos e IA } \\
\text { inerentes à web } \\
\text { - Parte desenvolvida, } \\
\text { resultados em } \\
\text { aplicação, e parte em } \\
\text { andamento. }\end{array}$ & $\begin{array}{l}\text { Desvendar o funcionamento dos } \\
\text { algoritmos e processos de IA das } \\
\text { redes sociotécnicas e motores de } \\
\text { busca e usar os conhecimentos } \\
\text { adquiridos para balizar decisões } \\
\text { editoriais, criar de narrativas e para a } \\
\text { distribuição de notícias. (BUCHER, } \\
\text { 2012; LATZER, 2016; DIAKOPOULOS, } \\
\text { 2019a; DIAKOPOULOS, 2019b; } \\
\text { PARISER, 2012) }\end{array}$ & $\begin{array}{c}\text { Observação participante e } \\
\text { levantamento de dados } \\
\text { estatísticos } \\
\text { (MALINOWSKI,1978) }\end{array}$ \\
\hline Desenvolvimento de & Desenvolvimento e implantação de & Entrevistas estruturadas e \\
\hline
\end{tabular}




\begin{tabular}{|c|c|c|}
\hline $\begin{array}{l}\text { aplicativo agregador } \\
\text { Parte desenvolvida, } \\
\text { resultados em } \\
\text { aplicação, e parte em } \\
\quad \text { andamento }\end{array}$ & $\begin{array}{l}\text { um app como uma das plataformas } \\
\text { do Campus e como agregador dos } \\
\text { conteúdos das demais plataformas } \\
\text { (LINS, 2020; WESTLUND, 2013) }\end{array}$ & $\begin{array}{c}\text { semiestruturadas (MARCONI } \\
\text { e LAKATOS,1996). } \\
\text { Observação participante } \\
\text { (MALINOWSKI,1978). }\end{array}$ \\
\hline $\begin{array}{l}\text { Desenvolvimento de } \\
\text { um chatbot } \\
\text { Parte desenvolvida, } \\
\text { parte em andamento }\end{array}$ & $\begin{array}{c}\text { Chatbot acoplável ao AppCampus } \\
\text { para responder leitores nas fases em } \\
\text { que o jornal fica sem produção. } \\
\text { (BRUNS, 2009) }\end{array}$ & $\begin{array}{l}\text { Entrevistas estruturadas e } \\
\text { semiestruturadas (MARCONI } \\
\text { e LAKATOS,1996). } \\
\text { Observação participante } \\
\text { (MALINOWSKI,1978). }\end{array}$ \\
\hline $\begin{array}{l}\text { Potencializar o uso do } \\
\text { App Campus no } \\
\text { aproveitamento dos } \\
\text { fluxos } \\
\text { comunicacionais } \\
\text { gerados pelos } \\
\text { algoritmos e IA das } \\
\text { redes sociotécnicas e } \\
\text { motores de busca } \\
\text { •Em andamento }\end{array}$ & $\begin{array}{l}\text { Potencializar a conexão entre apps } \\
\text { jornalísticos, algoritmos e sistemas de } \\
\text { IA inerentes à internet para otimizar a } \\
\text { distribuição automatizada de notícias, } \\
\text { balizar a tomada de decisões } \\
\text { editoriais e desenvolver aplicativos } \\
\text { inteligentes. (BUCHER, 2012; LATZER, } \\
\text { 2016; DIAKOPOULOS, 2019a; } \\
\text { DIAKOPOULOS, 2019b) }\end{array}$ & $\begin{array}{c}\text { Pesquisa criação (CHAPMAN } \\
\text { e SAWCHUK, 2012), } \\
\text { observação participante e } \\
\text { levantamento de dados } \\
\text { (MALINOWSKI,1978) }\end{array}$ \\
\hline $\begin{array}{l}\text { Desenvolvimento de } \\
\text { algoritmos } \\
\text { jornalísticos e } \\
\text { sistemas de IA } \\
\text { vinculados ao App } \\
\text { Campus } \\
\text { •Em planejamento }\end{array}$ & $\begin{array}{l}\text { Desenvolver algoritmos vinculados ao } \\
\text { AppCampus harmônicos com os } \\
\text { algoritmos e sistemas de IA inerentes } \\
\text { à web para otimizar a distribuição de } \\
\text { notícias e a tomada de decisões } \\
\text { editoriais. Produzir notícias } \\
\text { automaticamente. (HANSEN ET AL, } \\
\text { 2017; DIAKOPOULOS, 2019a; } \\
\text { DIAKOPOULOS, 2019b) }\end{array}$ & Metodologia em definição \\
\hline
\end{tabular}

Fonte: Elaborado pelo autor.

O foco atual das pesquisas em desenvolvimento é a aplicação de tecnologias comunicacionais no jornalismo e no ensino do jornalismo digital. Elas estão em diferentes estágios de desenvolvimento mas são simultâneas e se complementam.

A existência dos fluxos comunicacionais gerados pelos algoritmos e IA e o uso de alguns conhecimentos neste sentido para a tomada de decisões editoriais fazem parte das atividade do Campus desde a sua criação, mas agora a pesquisa neste sentido assume o protagonismo. Didaticamente, os estudos sobre as características de cada plataforma integra o programa das primeiras aulas do semestre. O tipo de público, os horários de maior movimento, as métricas das publicações e as potencialidades narrativas de cada rede sociotécnica são considerados posteriormente nas reuniões do Conselho Editorial para o planejamento das coberturas, definições de pautas, escolhas das narrativa, dos horários e plataformas de publicação. O que se pretende agora é criar processos próprios de automação. O mapeamento do workflow 
do Campus (ver Quadro 1) abriu caminho para o planejamento de uma ampla automação dos processos de produção porque explicitou toda a complexidade dos fluxos de trabalho e de tomada de decisão. Os workflows resultantes da pesquisa e os passos para a sua elaboração podem ser conhecidos em Barcellos e Silva (2020).

O trabalho pede participação intensa dos parceiros de outros cursos porque extrapola as habilidades usuais dos jornalistas. Mas, conforme Diakopoulus (2019a), a participação dos jornalistas na programação de algoritmos e sistemas de IA dedicados a tarefas jornalísticas é fundamental e passou a ser tarefa jornalística. Um primeiro passo nesse sentido foi concretizado no desenvolvimento de um chatbot acoplável à plataforma Facebook e que responde algumas perguntas básicas de leitores. A ideia é aprimorá-lo e instalá-lo no AppCampus.

Outro foco atual das pesquisas está relacionado justamente ao AppCampus, uma das principais atenções atuais da imprensa em geral. A fragmentação das notícias do Campus em sete plataformas e sua dispersão pelo ciberespaço levam à não percepção pelo público de que se trata de um único jornal. Logomarcas, cores e o mascote Campusito, uma foca estilizada, agregados aos conteúdos não têm sido suficientes para caracterizar a unicidade do jornal. Assim, há dois anos o Campus desenvolve um web aplicativo próprio, testado e aprovado em versão beta, para funcionar como plataforma agregadora das demais e reforçar a unicidade do jornal. $O$ app publica matérias multimídias resumindo as principais notícias publicadas nas demais plataformas com linkagens para elas. O app segue em aprimoramento em duas disciplinas de Jornalismo, e envolve alunos e professores de Jornalismo e Ciências da Computação da UnB.

A versão atual do app possibilita acesso direto às métricas fornecidas pelo Google Analytics (2020). A novidade permitiu o início de outra pesquisa para tentar desvendar alguns dos segredos dos algoritmos e processos de IAs escondidos pelos desenvolvedores (GALLOWAY, 2017; PARISER, 2012). Esta pesquisa também objetiva verificar o impacto na audiência das matérias publicadas na plataformas linkadas do AppCampus, e também conhecer melhor os receptores.

\section{Considerações}

O entrelaçamento das atividades teóricas e laboratoriais do jornal Campus Multiplataforma na disciplina Campus Multimídia revelou-se ambiente propício à pesquisa aplicada em duas vertentes. A primeira é o desenvolvimento de didática para o ensino do jornalismo digital capaz de acompanhar e até antecipar tendências da 
veloz evolução das tecnologias comunicacionais, e assim formar adequadamente pesquisadores e jornalistas. A segunda é desenvolvimento rápido de novas narrativas, veículos inovadores, sistemas de produção e distribuição de notícias e processos de de gerenciamento de produção.

A pesquisa aplicada também facilita a interdisciplinaridade com disciplinas do próprio Jornalismo, da Comunicação em geral, da Ciência da Computação e outras que tenham interfaces com o jornalismo digital. Para os alunos de disciplinas e grupos de pesquisas da área da computação, as experiências conjuntas têm sido forma dos alunos verem seus trabalhos aplicados em práticas em outras áreas, e para alunos de Jornalismo o trabalho interdisciplinar com a Computação é oportunidade de desenvolverem aparatos e sistemas informatizados, habilidades não totalmente contempladas nas disciplinas do curso. Outro aspecto que merece registro é a abertura de vários projetos de pesquisa que se entrelaçam e cujos resultados são complementares e/ou se retroalimentam.

A pesquisa aplicada configura-se como ambiente ideal para a iniciação científica dos alunos de graduação, para a formação grupos de estudos específicos dentro da própria disciplina Campus Multimídia, para o desenvolvimento de trabalhos de conclusão de curso, projetos de mestrado e propostas para o mercado de trabalho.

Por fim, fica em aberto o questionamento se a formação dos jornalistas deve contemplar disciplinas da área de informática, uma vez que a pesquisa descrita evidencia a necessidade de habilidades de programação, porém resolvidas até certo ponto graças a parcerias externas ao Departamento de Jornalismo e à Faculdade de Comunicação.

\section{Referências}

AALST, Will.; HEE, Kees. Workflow Management: Models, methods and systems. Eindhoven University of Technology: Eindhoven, 2000.

ADJUST GLOBAL APP TRENDS. Global Benchmarks Report, 2019. Adjust, 2019. Disponível em: <https://www.adjust.com/resources/ebooks/adjust-global-apptrends-report-

2019/?utm_source=Mobile\%20Marketing\%20Magazine\&utm_medium=CS\&utm_ campaign=UK_App\%20Trends\%202019\&utm_channel=1>. Acesso em: 20 mar. 2021.

BARBOSA, E. F.; MOURA, D. G. Metodologias ativas de aprendizagem na educação profissional e tecnológica. Boletim Técnico do Senac - Revista de Educação Profissional. Rio de Janeiro, v. 39, n.2, p. 49-67, maio/ago. 2013. Disponível em: <file://Users/zaneiramosbarcellos/Downloads/349-Texto\%20do\%20artigo-6991-10-20160829.pdf> . Acesso em: 16 mar. 2021. 
COMUNICAÇÃO, 40., 2017, Curitiba. Disponível em: <http://portalintercom.org.br/anais/nacional2017/resumos/R12-0342-1.pdf>. Acesso em: 29 mai. 2020.

BARCELLOS, Zanei; SILVA, Thalita Alves. Mapeamento do workflow do processo de produção de notícias multimídias para o jornal digital Campus Multiplataforma. In: CONGRESSO DE CIÊNCIAS DA COMUNICAÇÃO, 43. 2020, Parintins (remoto). Anais do $43^{\circ}$ Congresso de Ciências Da Comunicação: 2020, eletrônico. Disponível em: <http://www.intercom.org.br/sis/eventos/2020/resumos/R150533-1.pdf> . Acesso em: 17 mar. 2021.

BARCELLOS, Zanei.; GONZATTO, Rodrigo.; BOZZA, Gabriel. Jornalismo em segunda tela: webjornal produzido com dispositivos móveis em redação virtual. Sur le journalisme, About journalism, Sobre jornalismo, v. 3, n. 2, 15, dez. 2014. Disponível

em: <https://www.researchgate.net/publication/296706266_Jornalismo_em_segunda_ tela_Webjornal_produzido_com_dispositivos_moveis_em_redacao_virtual>. Acesso em: 24 abr. 2020.

BIVENS, Reena Kim. The internet, mobile phones and blogging: how new media are transforming traditional journalism. Journalism Practice, v. 2, n.1, p. 113-129, 2008.

BRUNS, A. Gatewatching: collaborative online news production. New York: Peter Lang Publishing, 2009.

BUCHER, Taina. Want to be on the top? Algorithmic power and the threat of invisibility on Facebook. New Media \& Society, v. 14, n. 7, p. 1164-1180, 2012.

CASTELLS, Manuel. A sociedade em rede. A era da informação, economia, sociedade e cultura, v.1. São Paulo: Paz e Terra, 1999.

CASTELLS, Manuel. Comunicación y poder. Madri: Alianza, 2012.

CETIC.BR - Centro Regional de Estudos para o Desenvolvimento da Sociedade da Informação. TIC domicílios - Indivíduos 2019. 2020. Disponível em: <https://cetic.br/pt/tics/domicilios/2019/individuos/>. Acesso em: 27, mai. 2020.

CHAPMAN, Owen; SAWCHUK, Kim. Research-Creation: Intervention, Analysis and Family Resemblances. Canadian Journal of Communication, v. 37, p. 5-26, 2012.

DEUZE, Mark; WITSCHGE, Tamara. Beyond journalism: Theorizing the transformation of journalism. Journalism, v. 19, n. 2, p. 165-181, 2018. Disponível em: <https://doi.org/10.1177/1464884916688550>. Acesso em: 14, jul. 2020.

DEUZE, Mark; YESHUA, Daphna. Online journalists face new ethical dilemmas. Lessons from the Netherlands. Journal of Mass Media Ethics, v. 16, n. 4, p. 273-292, 2001.

DIAKOPOULOS, Nicholas (a). Automating the news. Cambridge: Harvard University Press, 2109. Edição do Kindle.

DIAKOPOULOS, Nicholas (b). Inteligência artificial no jornalismo. Digi Labour, setembro, 2019. Disponível em: <https://digilabour.com.br/2019/09/20/inteligencia-artificial-no-jornalismoentrevista-com-diakopoulos/>. Acesso em: 28, jun. 2020.

FGV-EAESP - Fundação Getúlio Vargas - Escola de Administração de Empresas de São Paulo. 31 ${ }^{a}$ Pesquisa Anual do Uso da TI nas Empresas 2020. 2020. Disponível em: <https://eaesp.fgv.br/sites/eaesp.fgv.br/files/u68/fgvcia2020pesti-ppt.pdf>. Acesso em: 20, jul. 2020.

FLEURY, Maria Tereza Leme.; WERLANG, Sérgio. Pesquisa Aplicada - Conceitos e abordagens. In: Anuário de Pesquisa GVPesquisa 2016-2017. São Paulo: GVPesquisa, 2017. p.10-17. Disponível em: $<$ http://bibliotecadigital.fgv.br/ojs/index.php/apgvpesquisa/issue/view/4030/198 2>. Acesso em: 1 mar. 2021. 
FREIRE, Paulo. Pedagogy of the Oppressed. Nova York: Continuum International Publishing Group, 1993.

FREIRE, Paulo. The politics of education: culture, power and liberation. Boston: Bergin \& Garvey Publishers, 1985.

FREIRE, Paulo. Education for Critical Consciousness. New York: Continuum International Publishing Group, 1974.

GALLOWAY, Scott. Os quatro: Apple, Amazon, Facebook e Google - O segredo do gigantes da internet. São Paulo: HSM, 2017.

GEORGE, A. L.; BENNETT, A. Case Studies and Theory Development in the Social Sciences. Cambridge: Mit Press, 2005.

GIBSON, William. Neuromancer. Londres: Harper Collins, 1984.

GOOGLE MARKETING PLATAFORM. Google Analytcs. Disponível em: $<$ https://marketingplatform.google.com/intl/pt-BR_br/about/analytics/>. Acesso em: $1^{\circ}$, jun. 2020.

HANSEN, Mark; ROCA-SALES, Meritxell; KEEGAN, John; KING, George. Artificial intelligence: practise and implications for journalism. In: BROWN TOW CENTER FOR DIGITAL JOURNALISM - INSTITUTE FOR MEDIA INNOVATION, 2017 pdf. Disponível em: <https://www.researchgate.net/profile/Meritxell_RocaSales/publication/320988850_Artificial_Intelligence_Practice_and_Implications_for _Journalism/links/5a05d35c4585157013a35e45/Artificial-Intelligence-Practiceand-Implications-for-Journalism.pdf?origin=publication_detail>. Acesso em: 28 jun. 2020.

HOLTON, Avery E.; LEWIS, Seth C.; CODDINGTON, Mark. Interacting with audiences: Journalistic role conceptions, reciprocity, and perceptions about participation. Journalism Studies, v. 17, n. 7, p. 849-859, 2016.

JENKINS, Henry; GREEN, Joshua; FORD, Sam. Cultura da conexão: criando valor e significado por meio da mídia propagável. São Paulo: Aleph, 2014.

JENKINS, Henry. Cultura da convergência. São Paulo: Aleph, 2008.

KUENG, Lucy. Going digital: a roadmap for organisational transformation. Oxford: The Reuters Institute for The Study of Journalism, 2107.

LATZER, Michael; HOLLNBUNCHNER, Katharina; JUST, Natascha; SAURWEIN, Florian. The economics of algorithmic selection on the Internet. Working Paper - Media Change \& Innovation Division, vol. 7, n. 1, p. 3-33, 2014. Disponível em: $<\mathrm{http}$ ://www.mediachange.ch/media/pdf/publications/Economics_of_algorithmic_selectio n_WP_pdf $>$. Acesso: 7, mai. 2021.

LEVY, Pierre. Cibercultura. São Paulo: Ed. 34, 1999.

LINS, Arline. Aplicativos móveis: novas maneiras de produzir e distribuir notícia. In: SILVA Fernando Firmino da. (Org). Transmutações no jornalismo. EDUEPB: 2016, p. 45-72. Disponível em: <http://www.uepb.edu.br/download/ebooks/Transmutacoes-no-Jornalismo.pdf>. Acesso em: 24, mai. 2020.

LIVINGSTON, Sonia. The challenge of changing audiences: or, what is the audience researcher to do in the age of the Internet? European Journal of Communication, v. 19, n. 1, p. 75-86, 2004.

MALINOWSKI, B. Argonautas do Pacífico Ocidental. São Paulo: Abril Cultural, 1978.

MARCONI, Marina de Andrade.; LAKATOS, Eva Maria. Técnicas de pesquisa: planejamento e execução de pesquisas, amostragens e técnicas de pesquisas, elaboração, análise e interpretação de dados. 3.ed. São Paulo: Atlas, 1996.

MICROSOFT. The future computed: artificial intelligence and it's role in society. Redmont: 2018.

PARISER, Eli. O filtro invisível. O que a internet está escondendo de você. Rio de Janeiro: Zahar, 2012.

REUTERS INSTITUTE FOR THE STUDY OF JOURNALISM - Digital News Report 2020. Reuters Institute, University of Oxford: 2020 Disponível em: 
<https://reutersinstitute.politics.ox.ac.uk/sites/default/files/2020-

06/DNR_2020_FINAL.pdf>. Acesso em: 24, jun. 2020.

SALAVERRÍA, R. Redacción periodística en Internet. Espanha: Editora Eunsa. 2005.

SCOLARI, Carlos A. Transmidia sotorytelling: más allá de la ficción. Hipermidiaciones, 10 abril 2011. Disponível em: https://hipermediaciones.com/2011/04/10/transmediastorytelling-mas-alla-de-la-ficcion. Acesso em 12, mai. 2019.

STAKE, R. E. The art of case study research. Thousand Oaks: SAGE Publications, 1995.

TOFFLER, Alvin. A terceira onda. Rio de Janeiro: Record, 1980.

TRAQUINA, Nelson. Teorias do jornalismo: porque as notícias são como são. Florianópolis: Insular, 2005.

TRAQUINA, Nelson. Jornalismo Cívico: reforma ou revolução? In: TRAQUINA, Nelson; MESQUITA, Mário (Eds.). Jornalismo Cívico. Lisboa: Livros Horizonte, 2003. p. 9-17

WE ARE SOCIAL. Digital 2020 april global statshotl. 2020. Disponível em: $<$ https://wearesocial-net.s3.amazonaws.com/uk/wpcontent/uploads/sites/2/2020/04/03-Device-Time-Increase-OverallDataReportal-20200422-Digital-2020-April-Global-Statshot-Report-Slide-9.png > Acesso em 24, mai. 2020.

WESTLUND, O. Mobile news: areview and model of journalism in an age of mobile media. In: Digital Journalism. v. 1, n. 1, 2013. p. 6-26.

\begin{abstract}
:
The internet is the main source of news for Brazilians, the smartphone is the preferred device for access and social networks have displaced television as a hegemonic medium. Fragmented journalism demands new narratives, vehicle formats, production and distribution processes. The algorithms and systems of artificial intelligence (AI) already perform many tasks, the profession is reconfigured and the teaching of digital journalism needs to keep up with the changes. This article proposes multifaceted applied research as a way to develop narratives, devices, production management systems and didactics capable of following technological developments and training journalists able to research and work in changing environments.
\end{abstract}

KEYWORDS: Digital journalism; applied research; multiplataform, artificial intelligence.

\section{RESUMEN:}

Internet es la principal fuente de noticias para los brasileños, el teléfono inteligente es el dispositivo preferido de acceso y las redes sociales han desplazado a la televisión como medio hegemónico. El periodismo fragmentado demanda nuevas narrativas, formatos de vehículos, procesos de producción y distribución. Los algoritmos y sistemas de inteligencia artificial (IA) ya realizan muchas tareas, la profesión se reconfigura y la enseñanza del periodismo digital necesita mantenerse al día con los cambios. Este artículo propone la investigación aplicada polifacética para desarrollar narrativas, dispositivos, sistemas de gestión de la producción y didácticas capaces formar periodistas capaces de investigar y trabajar en entornos cambiantes.

PALABRAS CLAVE: Periodismo digital; investigación aplicada; multiplataforma; inteligencia artificial. 